\title{
OPEN
}

\section{Introduction: On the Concept of Cross-European Technology Assessment}

\section{Rasmus Øjvind Nielsen and Lars Klüver}

\begin{abstract}
Nielsen and Klüver introduce the concept of cross-European technology assessment developed in the PACITA project, the layers of which are unfolded in the remaining chapters of this book. As a supplement to existing European institutions, cross-European technology assessment is a vision of a networked support system for national parliaments supplying process-support for knowledge-based and participatory policy making. As well as discussing the possible role of such a support system within existing European frameworks of policy formation, Nielsen and Klüver propose the necessity of capacity building modelled on the concept of cross-European technology assessment as a means to counterbalance trends towards European centralization in the face of grand societal challenges.

Klüver, Lars, Rasmus Øjvind Nielsen, and Marie Louise Jørgensen, eds. Policy-Oriented Technology Assessment Across Europe: Expanding Capacities. Basingstoke: Palgrave Macmillan, 2016. DOI: 10.1057/9781137561725.0007.
\end{abstract}


European societies are pushed and pulled by tremendous forces in many directions at once. Science and technology has provided Europe and the world with incredible advances in production, health care, communication and almost any other aspect of human life. But our resource-hungry systems of production and consumption strain the supporting capacities of natural ecosystems, and we are moving from an era of abundance to one of scarcity. In a world of globally interconnected economies, systemic risks seem to increase exponentially and to far surpass the traditional managing capacities of nation states. Too often, however, the backbone reaction of decision makers is to invoke protocols of crisis management: gathering control in governmental centres and placing authority in the hands of narrow elites. In the case of the science-society relationship, large-scale research and innovation efforts accompanied by centralized social engineering regains prominence as decision makers attempt to take effective action. But while better knowledge and smarter solutions must undoubtedly be part of Europe's way forward, centralization in itself presents a danger to the social fabric of societies. Whenever societal decision making is disconnected from the perspectives of those that feel its consequences in their daily lives, alienation and dissatisfaction enters the relationship between governments and citizens. Attempts to address the grand societal challenges of our time must therefore first face the necessity of building capacities for effective democratic governance. Each step towards stronger centralized capacities for action must be accompanied by equal steps to build capacities for problematizing evidence, debating values and adapting solutions to fit local needs and cultural contexts.

The core message of this book is that technology assessment holds at least some of the needed answers for how we can build such decentralized capacities for knowledge-based democratic decision making. Technology assessment (TA) is a discipline of public administration that seeks to build bridges between research and innovation, society at large and political decision makers. To operationalize this institutional mission, a wide range of methods have been developed that enable TA organizations to dynamically address different gaps of knowledge and communication in different societal situations. As such, TA may be viewed as an institutional answer to the problem of governing research and innovation responsibly, where the problem of governance is seen first and foremost as a problem of decoupling between the different kinds of knowledge and different sets of values held by different societal actors. 


\section{The emergence of a diverse policy support function}

TA began as an interdisciplinary academic endeavour in the 1960s, at which time the long-term risks from indiscriminate use of modern chemical and nuclear technologies was becoming increasingly clear. Pitted against an establishment unwilling to admit to its own errors of judgement, TA first took the form of 'reactive' movement within academia, aiming to provide alternative evidence to support advocacy of mainly environmental protection and work-place conditions. This 'watchdog' role was expanded institutionally in the US at the national level when Congress established its Office of Technology Assessment (OTA) in 1972. Here TA - or parliamentary TA (PTA) as it came to be known - would act as analytical support to congressional oversight of the societal opportunities and consequences of the technological development.

TA was one of several strands of new, interdisciplinary forms of analysis seeking to provide guidance for decision makers in advanced industrial societies. Environmental impact assessment, risk assessment, foresight studies, technology ethics and the cross-disciplinary field of science-and-technology-studies (STS) all have their historical roots and institutional raison dêtre in the apparent complexity of governing modern technology and the loss of popular trust suffered by experts and industrial stakeholders. There are many overlaps between these traditions in terms both of pragmatics of method and outlooks regarding the science-society relationship. The lines between TA and non-TA are thus not sharply drawn, and the different traditions mentioned continue to enrich each other.

In Europe, the first proposals for establishing capacities similar to that of the OTA were made immediately after the first round of European expansion in 1973. The idea of a common European Office of Technology Assessment, however, proved difficult for the member states to swallow, and a centralized unit dedicated to technology assessment and foresight would not see the light of day until the establishment of the Institute of Prospective Technology Studies (IPTS) as a subunit of the Joint Research Centre in 1992. Meanwhile, the TA concept had more immediate rapport with the individual national parliaments in Western Europe and the European Parliament itself. Beginning in the early 1980 os and inspired by processes of knowledge sharing within the Commission-driven FAST program, TA institutions were established in connection with parliaments in Denmark, France, 
Germany, the Netherlands and the United Kingdom. An office for Science and Technology Options Assessment (STOA) was set up in connection with the European Parliament in 1987. At later stages, PTA organizations were also established in Belgium, Finland, Greece, Italy, Norway, Spain, Sweden and Switzerland while TA organizations, but without the 'P', established in Austria, the Czech Republic and within the Council of Europe have also been part of the landscape of TA in Europe (see also Chapter 1 and Chapter 2). Over the years, these TA institutions developed more 'proactive' roles for TA in supporting policy development. TA became closely linked with foresight studies and now shares the attempts to identify desirable pathways for development through forward-looking exercises. Some TA institutions took part in developing 'constructive' TA approaches to embed reflection on ethical, legal and social aspects (ELSA) in the development process itself. Other institutions developed methods for citizen participation and stakeholder inclusion in policy development for technological innovation and planning, precipitating the 'deliberative turn' in research and innovation policy. Today, TA thus walks on two legs: policy analysis and public engagement.

Since at least the turn of the millennium, the stakes of science and technology policy have been raised significantly. The perspectives of impending climate change and peak oil, which have been accompanied by increasing global competition in innovation, have driven science and technology policy towards more complex forms of reflexive governance. In this situation, the European TA field has increasingly sought to consolidate its methods and to provide 'strategic intelligence' for European policy makers acting at both national and European levels. The European Parliamentary Technology Assessment (EPTA) network was established in 1990 to enable cooperation among dedicated parliamentary TA units and units with similar goals. The IPTS has increasingly sought to orchestrate deliberation at European level between different TA and foresight organizations. And various parliamentary and non-parliamentary TA organizations have been increasingly involved in the European Commission's framework program for research, especially under those lines of research which are today known as Science with and for Society (SWAFS). 


\section{Mobilizing TA for grand challenges - the PACITA Project}

The PACITA (Parliaments and Civil Society in Technology Assessment) project was set up under the 7 th European Framework Program for research and development. It ran from 2011 to 2015 and was coordinated by the Danish Board of Technology. Working under the assumption that TA will need to adapt to the change towards the internationalization of science, technology and policy, the project's overarching goal was to mobilize and expand the European TA community through processes of mutual experimentation and learning. Through such expansion, the working hypothesis of the project was that the TA field can grow into a Europe-wide support system for broadening the knowledge base of policy making in Europe. Helping to spread nationally based arrangements for providing TA services across Europe would serve the triple purpose of supporting national parliaments and governments, supporting and connecting national democracies across Europe in transnational dialogue and collaboration and helping to strengthen the bottom-up dimension of European democratic governance. We call this distributed support system 'cross-European TA'.

The PACITA strategy for an expanding TA field was bound up with a strengthening of national democratic institutions. In the four-year course of the project, it gathered a group of fifteen partner organizations from different European countries in collaborative processes, which were at once linked to European agendas and based on national debates. Among these partners, some are established TA organizations connected to parliaments or otherwise formally organized to support national policy (the partners from Austria, Belgium (Flanders), Denmark, Germany, the Netherlands, Norway, Spain and Switzerland), while others are organizations with closely related missions interested in developing locally appropriate institutional models for TA (the partners from Belgium (Wallonia), Bulgaria, the Czech Republic, Hungary, Ireland and Portugal). Among the members of this group, enough diversity with regard to national settings was represented that the outcome of the project would be applicable across $\mathrm{EU}_{28} 8$ and the group of associated or candidate countries. 


\section{Main findings of the project}

The project pursued four operational aims, the outcomes of which are documented in this book. The first aim was to map and conceptually categorize existing PTA institutions and practices. The second aim was to help guide countries, which as yet had no such dedicated TA functions, in establishing TA institutions appropriate for their specific culture and settings. The third goal was to showcase and give hands-on experiences with the praxis, methodologies, outcomes and social value of collaboration among TA institutions across Europe. Finally, the fourth goal was to begin the process of building up mutual capacities for training and communicating TA practice and results in order to build a cross-European TA capacity of infrastructures and human resources.

To what extend are the goals of such a project realistic? It is of key importance to assess the contributions as well as the limitations of what has been attempted. A key issue in this regard is the question of methods and how well they travel from their original national contexts to other cultures and to cross-national collaborations. For example, PACITA carried out a process of stakeholder deliberations on the future of ageing in which national responses were formulated to strategies developed at European level (see Chapter 7). Here, it was clear that the national processes in and of themselves were both politically useful and perceived as legitimate by the participants. And from a trans-European point of view, the simultaneous but nationally particular formation of ideas for policy presents a potentially highly valuable addition to the general European policy-formation process. But we must acknowledge at the same time that without a clear institutional mandate within the overall process of European policy formation, the recommendations produced by such nationally based bottom-up processes risk drowning in the whirlwind of European debates. Similarly, institutional issues produced profound challenges to an experiment in which the PACITA partners orchestrated a cross-national Future Panel. The Future Panel is a process in which parliamentarians from across the political spectrum take part in a common process of learning and forming opinions about complex issues that arise from science and technology. In this case, a cross-national panel would gather to learn about and debate the possible contributions of advanced genomics research to public health care in the future (see Chapter 6). Here again, while those parliamentarians 
who did take part were positively surprised and enthused by the spirit of deliberative inquiry that is embodied in the Future Panel, it was the lack of a common mandate from the involved parliaments which proved to be a stumbling block in the recruitment of parliamentarians for participation.

The benefits, however, should not be underplayed. A third PACITA experiment focused on public engagement and gathered citizens in different European member states in citizen summits to deliberate on the complex trade-offs involved in policy for sustainable consumption (see Chapter 8). This experiment provided strong indications that, when applied to the cross-European level, a deliberative take on public engagement seems to be a viable strategy for squaring the circle of democratic involvement in centralized European policy making. Simultaneous national processes in which citizens are briefed on the best available knowledge and afforded time to deliberate in socially diverse groups provides high-quality, nationally founded, but still 'European' inputs to the European policy process.

Looking at the method dimensions, the PACITA model of bottom-up development of cross-European TA that organized and operationalized by existing and emerging TA institutions and that was supported by the European Commission seems to be a viable pathway for sowing the seeds of cross-European TA. The outcomes of the project are surely tangible and promising. But at the same time, the PACITA project covered only fifteen countries and, as such, was an experiment, though a successful one. Ultimately, the idea of a Europe-wide implementation of TA must be taken up politically and given a mandate in order for cross-European applications of TA methods to really work.

The PACITA project may be said to have expanded European TA capacities in at least four different dimensions:

Geographically: We have aimed at expanding the capacity and formal institutionalization across Europe and have succeeded in doing that perhaps more importantly, we have also sown seeds for further expansion in the future.

Collaboratively: Developing cross-European TA for the benefit of Europe as well as for the member states has been a core aim of PACITA, and we have definitely proved that there is a large need for this and that there are big potentials in developing a truly European collaborative space for TA. 
Conceptually: The background, context and function of existing TA institutes have been scrutinized intensely with important new insights in the role and function of TA as a result.

Conceptually: The background, context and function of existing TA institutes have been scrutinized intensely with important new insights in the role and function of TA as a result.

Politically: At two parliamentary meetings with representatives from the EPTA and PACITA countries and beyond, it was clearly stated by the MPs that TA has a very important role to play for EU, Europe in a wider sense, and for the EU member states. A clear call has been made for a strong Commission engagement in widening the TA landscape in Europe and in providing options for new countries to take up TA.

\section{Why cross-European TA?}

What this book substantiates is the claim that going forward, the issue is not whether cross-European TA is possible. The book shows that the needed professional approaches exist, the national capacities can be built - often on the shoulders of existing ones - and collaboration between institutions distributed across Europe can be brought to work. Rather, the question is whether and why European policy makers and parliamentarians at national and transnational levels ought to support a vision of the development of cross-European TA capacities. The remainder of this introduction is dedicated to providing a frame in which to answer this question.

To begin with, we should try to get at the overall question whether there is in fact a need to strengthen national level capacities for policy analysis and public deliberation. The standard counterargument is that with global challenges we need global solutions and a strengthening of transnational decision-making capacities. For many, a 'return' to the nation state is unrealistic and represents in any case a step backwards. We are, however, not arguing for a 'return' to the nation state and a purely intergovernmental mode of European collaboration. On the contrary, our argument is that national democracies need strengthening in order to take their proper place in European - or global - multilevel governance.

The cornerstone of European collaboration remains the subsidiarity principle. And while the future will tell whether European collaboration will grow into federation, the sign of the times do not point in 
that direction. A realistic approach to drawing on Europe's collective strengths to efficiently address grand challenges must therefore take seriously the continuing role of national member states as a crucial level of policy adaption to local contexts. By the same token, with the process of European integration halted somewhere between inter-governmentalism and federated statehood, European institutions remain systematically under-democratized. Consequently, the national parliaments will remain privileged as fora for maintaining true European democracy.

What remains true logically, however, is challenged in real life. At the national level, the capacities of parliaments to act as counterweight to national executives have been systematically weakened by European integration. Parliaments have less formal access to providing input to common European policy processes than do governments. Parliaments therefore end up on the receiving end of the policy process, and the diversity of input that they represent is narrowed significantly. A similar effect of narrowing democratic diversity can be traced in the representative function of political parties. Here, the process of European integration has led the major centre parties in each member state to crowd around common middle positions compatible enough with the European mainstream to be strategically viable.

This process of consensus-building that centres on 'necessary' rather than 'wished' policies is amplified by the national economic strategic idea of the 'competition state' - the conception that international competition forces nations to act as if they were large companies. This conception has had highly detrimental effects on the range of futures and policies being imagined, and politically, it has inhibited the agility of centre parties, thus weakening parliamentary collaboration across parties.

The need for strengthening national parliaments is not about strengthening individual nations against the European community, nor is it a call for dis-integration. Rather, it is a call for strengthening precisely the part of the European system, which must be strong if Europe is to become legitimate

\section{The role of cross-European TA in European governance}

The inadequacies of the national and regional levels of governance are well understood and lie at the heart of the motivation for the development 
of the European Union in the first place. The capacities needed to continuously modernize society's infrastructure through research and development have long surpassed the size of the purses of individual nations. Consequently, cooperation on the advancement of research was one of the very first issue areas where the logic of cooperation became clear to European member states. Likewise, the scale of the mechanisms needed to render innovation economically viable has outgrown national markets. This is why the common European market has been a central guiding star for Europe for more than a generation and the European Research Area has such a prominent position.

With the pooling of innovative resources and merging of markets, much of the regulatory ability of member states has also shifted to the European level. One the one hand, this has allowed Europe to build a global region protected by the most progressive environmental and social protections in the world. But on the other hand, along with global deregulation to enhance trade flow, this shift has contributed to a lock-in situation for member states where increased cooperation is often not an option but the only viable path. Single member states are at a great disadvantage in relation to globalized industries and financial actors able to move production and capital from one country to the next. Countries wishing to move environmental and social policy forward - tools that will likely prove crucial in addressing grand challenges - are often bound to negotiate such changes within the traditional framework of European decision making known as the 'community method'. This is the framework in which national executives gathered as the Council of Ministers set out policy goals, which are then fleshed out in regulatory proposals by the European Commission to be approved by the European Parliament and ultimately the Council itself.

Often cited democratic dilemmas and deficiencies of the community method have led to the formulation of alternative governance strategies. The European Commission, for instance, has increasingly made use of soft governance approaches to coordinate societal actors around common goals. We see this in the response of the Commission to the Lund Declaration in the Europe 2020 strategy. Here public-private partnerships and networking initiatives meant to stimulate self-governance within industry are combined with a focus on societally strategic research and innovation. A cross-cutting framework to structure the self-governance of actors that participate in these strategic exercises is emerging under the title 'responsible research and innovation' (RRI). Within this framework, 
participation in research and innovation activities funded or otherwise stimulated by the Commission will be dependent on the willingness to undertake self-governance measures to align R\&I output with the needs of society. Such measures, whichever practical form they may take, shall enact the principles of inclusiveness, anticipation, reflexivity and responsiveness. The ideal embedded in these principles is those of a selfregulatory system of multiple societal actors able to converge on common goals through ongoing dialogue and mutual learning. To a very large extent, this ideal has always been shared by the technology assessment community. Whether TA has been reactive, proactive, 'constructive' or 'participatory', TA has always sought to embed upstream societal reflections in the real-world processes of science, technology and innovation policy, precisely to achieve outcomes that would be already well rounded and aligned with the needs and values of multiple societal actors. The only major point at which the TA project still stands out from the RRI framework - and the point around which the unique value TA may add to RRI crystalizes - is the practical and institutional commitment to retain and strengthen the embedding of such soft governance approaches in the institutions of representative democracy.

Cross-European TA - still in the sense of national policy-oriented TA bodies in all states collaborating at European level - may thus play a number of important roles in consolidating the ideas in modern European governance:

- The need to strengthen national parliaments in the EU is broadly acknowledged, but the structures to facilitate that change are lacking. Here, TA can play an important role by serving parliaments with knowledge, analysis and debate on EU developments in science, technology and innovation.

- The importance of the subsidiarity principle is greater than ever, but adhering to it may produce locked decision-making situations under the community method. Circumventing such dead ends demands the creation of spaces for open explorative dialogue across the EU, involving citizens, stakeholders and parliaments. TA has longstanding traditions which make it an obvious player for creating such cross-European analytical dialogue.

- Governments are forced to become more and more European, while parliaments become increasingly national - some may even say provincial. TA can build bridges for parliaments across Europe, 
thereby enhancing the connection between parliamentary debates and European developments.

- The EU needs to get in contact with citizens and to support the emergence of a true 'European public', but it faces a lack of European identity. With national TA institutions in place, a platform emerges with the legitimacy to engage and consult citizens on the national level and connect the outcomes at the EU level which makes TA a potentially perfect partner for both the national and the EU level governance.

- Cross-European TA collaboration can add to the smart specialization aims by, on the one hand, facilitating the needed discourse at the national level and, on the other hand, ensuring that it is connected across Europe - allowing for a certain level of coordination of the specialization.

- TA at the national level is an important factor for having a rich analysis and conversation about the societal opportunities and challenges stemming from science, technology and innovation. Having TA institutionalized in all European states will provide an opportunity for expanding that analysis and conversation to the European level and creating much needed links between the multiple levels of the European governance system.

The PACITA consortium has on the basis of these thoughts and the lessons of the PACITA project provided the TA Manifesto, which has gained support from more than 300 signatories. ${ }^{1}$

\section{Note}

1 See http://www.pacitaproject.eu/ta-manifesto/.

Except where otherwise noted, this work is licensed under a Creative Commons Attribution 4.0 Unported License. To view a copy of this license, visit https://creativecommons.org/version4 